\title{
NATUREZA DA CRENÇA EM DAVID HUME
}

\section{Lucas Jairo Cervantes Bispo'; Wagner Teles de Oliveira ${ }^{2}$;}

1. Bolsista FAPESB, Graduando em Filosofia, Universidade Estadual de Feira de Santana, e-mail: ljcbispo@outlook.com 2. Orientador, Departamento de Ciências Humanas e Filosofia, Universidade Estadual de Feira de Santana, e-mail: woteles@gmail.com

PALAVRAS-CHAVE: Epistemologia; Crença; Milagres.

\section{INTRODUÇÃO}

Segundo David Hume, a vida de cada um de nós está recheada de certezas que ultrapassam os registros de nossa memória e o testemunho presente dos nossos sentidos, isto porque não tratam do passado nem do presente. São certezas acerca do futuro. Estas certezas podem existir em nós com tamanha força que sequer estão em nossas mentes como alternativas, entre outras, nas quais notamos que cremos. Podem estar dadas naturalmente tão quanto ocorre de estarmos respirando sem consciência disto. Por exemplo: ao caminharmos, não há dúvida em nossas mentes a cada passo que damos de que a lei da gravidade irá continuar funcionando como sempre funcionou, ainda que nossa imaginação possa conceber que viesse a mudar. A certeza já está incutida no próprio ato sem que nós pensemos nesta questão. Essa certeza aparece ainda que reflitamos acerca duma questão dessas. Se alguém segura uma caneta e nos pergunta o que ocorrerá se solta-la, ainda que possamos imaginar que ela subirá ou parará no ar, cremos, afirmaria Hume, na alternativa de que irá cair. Este autor nos dirá que este tipo de certeza se refere a uma categoria de objetos da investigação humana que chama de Questões de Fato, que se caracteriza por o contrário do que é pensado ser sempre possível e não implicar contradição. Exemplifica que a afirmação que o sol não nascerá amanhã não é menos inteligível nem implica mais contradição que a afirmação de que ele nascerá, visto que a mente concebe ambas com a mesma facilidade e clareza como possibilidades ajustáveis à realidade, de modo que seria vão tentar demonstrar sua falsidade, pois se fosse demonstrativamente falsa sequer a mente poderia concebê-la distintamente na medida que implicaria uma contradição. Fica a questão: o que nos da garantias, para além do testemunho presente de nossos sentidos ou dos registros de nossa memória, quanto a qualquer questão de fato sobre o futuro? Isto é, o que nos faz crer que no próximo segundo a lei da gravidade continuará funcionando ou que a caneta cairá se solta? Ao tratar sobre as questões de fato, interessado na natureza das evidências neste tipo de investigação, afirma que se nos perguntarmos o que nos da garantias, encontraremos um processo que resulta no que chamou de crença. Há, no entanto, uma crença que possui outra configuração tratada por Hume na seção 10 de suas Investigações Acerca do Entendimento Humano (1748). Esta é a crença em milagres a partir do testemunho de terceiros. "Outra configuração" porque além de não poder ser explicada totalmente pelo processo de formação de crenças descrito primeiramente na obra, nosso autor concluirá que nenhum testemunho de terceiro é suficiente para estabelecer um milagre se em contexto religioso e com pretensão de fundar um sistema religioso com o caráter do que este autor chamou de "religiões populares", como também os não-religiosos ao menos que a falsidade destes fosse ainda mais miraculosa do que o fato que pretendem estabelecer - acontecimento este que, segundo Hume, nunca houve demonstrativamente, e numa segunda posição que talvez seja impossível encontrar algum assim em todos os registros da historia. Não obstante as conclusões anteriores, ainda assim há quem creia, a partir de testemunhos, que milagres ocorreram. Sendo assim, a presente pesquisa tomou como objeto de investigação a seguinte questão: qual seria a natureza dessa crença na perspectiva humeana? 


\section{MATERIAL E MÉTODOS OU METODOLOGIA (ou equivalente)}

O método de pesquisa em filosofia consiste na leitura e escrita de textos segundo técnicas de exegese e de escrita que caracterizam a atuação profissional na área. Assim, a execução das atividades concernidas pelo plano de trabalho privilegiou o cotejo das fontes primárias da pesquisa, sobretudo a Investigação Acerca do Entendimento Humano, sem se furtar à apreciação de fontes secundárias, textos de destacados comentadores, que se inscrevem na tradição de leitura da obra de David Hume, como Carlos Alberto Ribeiro de Moura e João Paulo Monteiro. Nesse sentido, o trabalho de pesquisa consistiu em duas etapas. Em uma primeira etapa, a da leitura, os textos indispensáveis à pesquisa foram cuidadosamente fichados. Em uma segunda etapa, a da escrita, uma vez vencida a etapa da leitura, foi elaborado um texto monográfico que foi gradativamente apresentado nas reuniões de nosso Grupo de Estudo e Pesquisa, de modo a permitir a apreciação dos resultados parciais da pesquisa por meio do debate das questões que ela envolve.

\section{RESULTADOS E/OU DISCUSSÃO (ou Análise e discussão dos resultados)}

Conforme Hume, quando um objeto nos é apresentado à memória ou aos sentidos, através dos princípios de associação de idéias, o hábito nos leva, pela imaginação, a conceber o objeto que lhe está usualmente associado, e esta concepção é acrescentada de um sentimento, tornando tal idéia uma crença e diferindo-a das ficções. Dessa forma, mesmo sendo a mente humana livre para associar e transformar as idéias fornecidas pelos sentidos internos e externos, não pode acrescentar a estas idéias o que lhes falta para que a mente possa acreditar com certeza no concebido. Nas palavras de Hume, "a crença nada mais é que uma concepção de um objeto mais vívida, vigorosa, enérgica, firme e constante do que jamais seria possível obter apenas pela imaginação" (Hume, 1748). Ou ainda: "[...] ato mental que torna as realidades - ou o que se considera como tais - mais presentes para nós do que as ficções, que lhes dão um peso maior junto ao pensamento e uma influência superior sobre as paixões e a imaginação" (Hume, 1748).

Esta crença será mais ou menos forte em termos de certeza a depender de se a experiência para nós se constitui como uma prova ou somente nos dá níveis de probabilidade. Uma prova se forma quando na experiência uma causa gera um certo efeito de modo uniforme e constante, como o fogo que sempre queimou e a água que sempre afogou. A probabilidade quando efeitos diferentes se seguem de causas aparentemente em tudo semelhantes, como o ruibarbo que nem sempre funcionou como um purgante ou o ópio como um soporífero.

Isto posto, como o hábito nos leva em nossas inferências a transferir o passado para o futuro, quando a experiência se constitui como prova nós esperamos o efeito com máxima segurança, já quando como probabilidade, os diferentes efeitos devem se apresentar a mente que dará maior preferência ao que se mostrou mais usual. No entanto apesar de virmos a crer mais no efeito usual do que nos menos usuais, Hume nos diz que não podemos negligenciar os demais e a cada um deles cedermos peso e autoridade na medida em que ocorreram com maior ou menor freqüência. Um homem sábio, afirma Hume, dosa sua crença em proporção à evidência.

Há, no entanto, uma crença que possui outra configuração tratada por Hume na seção 10 de suas Investigações Acerca do Entendimento Humano (1748). Esta é a crença em milagres a partir do testemunho de terceiros. "Outra configuração" porque além de não poder ser explicada totalmente pelo processo de formação de crenças descrito anteriormente, como foi argumento no artigo final da pesquisa, nosso autor concluirá que nenhum testemunho de terceiro é suficiente para estabelecer um milagre se em contexto religioso e com pretensão de 
fundar um sistema religioso com o caráter do que este autor chamou de "religiões populares", como também os não-religiosos ao menos que a falsidade destes fosse ainda mais miraculosa do que o fato que pretendem estabelecer - acontecimento este que, segundo Hume, nunca houve demonstrativamente, e numa segunda posição que talvez seja impossível encontrar algum assim em todos os registros da historia.

Não obstante as conclusões anteriores, que foram sustentadas argumentativamente no artigo final, ainda assim há quem creia, a partir de testemunhos, que milagres ocorreram. Qual seria a natureza dessa crença na perspectiva humeana? Entendemos que esta não pode se formar única e exclusivamente a partir do processo no qual a crença seria edificada a partir de uma noção de conexão entre causa e efeito derivada de uma experiência habitual de conjunção entre acontecimentos que se seguem, isto porque se por definição o milagre pressupõe uma regularidade anterior, a própria regularidade denuncia o fato de não haver a experiência habitual de milagres. Ou seja, se é um milagre que um homem morto ressuscite, é preciso que habitualmente, de forma regular e invariável, homens mortos não ressuscitem. Ademais, não se trata aqui de uma crença derivada da experiência de um milagre em confronto com uma experiência anterior que constitui uma prova, mas derivada sim do testemunho, do relato, de terceiros acerca do milagre - o qual, segundo Hume e como expomos, não pode tornar o suposto milagre digno de crédito.

Nas Investigações, apesar da máxima geral pela qual comumente conduzimos nossos raciocínios ser esta na qual objetos dos quais não temos experiência se assemelharem aos quais temos, que o mais usual é sempre mais provável e que onde há oposição de argumentos devemos dar a preferência ao que está apoiado por maior numero de observações, emoções agradáveis como a paixão da surpresa e do assombro podem nos fazer crer em relatos miraculosos ainda que ilegitimamente. Os exemplos históricos de milagres e profecias que foram desmascarados evidenciam esta forte propensão da humanidade para o extraordinário e fantástico. Quando esse amor pelo maravilhoso junta-se ao espírito de religiosidade, dirá Hume, menor força terá o bom senso para julgar.

Nesse sentido afirma no Tratado da Natureza Humana (1738) que "Possuímos uma notável propensão a crer em tudo que nos é relatado, mesmo no caso de aparições, encantamentos e prodígios, por mais contrários que sejam a experiência e a observação diárias" (Hume, 1737).

Outros fatores que podem contribuir para esta crença é a falta de discernimento para analisar as provas apresentadas por parte do testemunho, a abstenção de utilizar o discernimento para analisar as provas devido ao mistério, a utilização do discernimento sob a influência das paixões que perturbam a regularidade das operações, como também o poder da eloqüência dos testemunhos que enfraquece a razão e dirigindo-se aos afetos e a imaginação cativa os ouvintes condescendentes e subjuga-lhes o entendimento.

\section{CONSIDERAÇÕES FINAIS (ou Conclusão)}

A crença em eventos miraculosos a partir do testemunho de terceiros pode encontrar alguma sustentação razoável, numa perspectiva humeana e dentro dos limites dessa pesquisa, se for não-religioso e sua falsidade for ainda mais miraculosa do que o que propõe. Fora isto a crença não encontraria respaldo na experiência e num bom modo de raciocinar, encontrando sua natureza em emoções agradáveis como a paixão da surpresa e do assombro, na utilização do discernimento sob influencia dessas emoções, na falta de discernimento ou abstenção de 
utilizá-lo, no amor pelo maravilhoso, no poder afetivo de convencimento dos testemunhos e também numa inclinação natural para crença no extraordinário.

\section{REFERÊNCIAS}

HUME, DAVID. Tratado da natureza humana. UNESP: São Paulo, 2001.

. Uma investigação sobre o entendimento humano. UNESP: São Paulo, 2004.

ALBIERI, SARA. "Crença e Aceitação: A Teoria Humeana da Crença como Conhecimento Confiável.” In: GUIMARÃES, Lívia (org.). Ensaios Sobre Hume (II Colóquio Hume), p. 79 88. Belo Horizonte: Editora Segrac, 2005.

MONTEIRO, JOÃO PAULO. Hume e a epistemologia. Imprensa Nacional Casa da Moeda: Lisboa, 1984.

jan/jun, 2005.

. "Hume: Três Problemas Centrais". Dois Pontos, Curitiba, Vol. 1, n. 2, p.111 - 128,

MOURA, CARLOS ALBERTO RIBEIRO DE. Racionalidade e crise. Discurso Editorial e Editora da UFPR: São Paulo, 2001. 